\title{
Escuchar lo que dicen los pobres a la Iglesia*
}

\author{
José M. Castillo, \\ Centro de Reflexión Teológica, \\ San Salvador.
}

\section{Introducción}

A la Iglesia se le plantean muchas cuestiones en este momento. Y sobre la Iglesia, la gente se hace muchas preguntas. Pero, ahora mismo, hay algo que pesa más que todo lo demás. Lo más grave, lo más urgente. ¿De qué se trata? Estamos acabando el siglo más violento de toda la historia de la humanidad. Hasta tal extremo, que resulta sencillamente imposible calcular, de manera más o menos aproximada, los millones de muertos que han sido víctimas de las dos guerras mundiales y de los cientos de otras guerras que han arrasado y siguen arrasando a pueblos enteros. Pero la violencia más aterradora de este siglo ni ha sido, ni es, la violencia de las guerras.

La violencia mayor, la que más muertos ha coslado, la que sigue destruyendo más vidas humanas, es la violencia que resulta de la economía, concretamente de la economía del mercado neoliberal, tal como está organizado $y$ tal como funciona de hecho.

\subsection{No es una cuestión de tantas}

No es una exageración. Ni una afirmación gratuita. Se sabe que, en la actualidad, se produce un 10 por ciento más de los alimentos que necesitamos para vivir toda la humanidad $y$, sin embargo, mueren de hambre 35,000 niños

* En los númcros 44 y 45 de csta revista, en 1998 aparccieron dos artículos de José María Castillo sobre "Jesús, el pueblo y la teología". Publicamos ahora otro texio suyo, que es una especie de aplicación de los artículos anteriores a la cclesiología. Ha aparecido ya como cuaderno df Cristiagisme i Justicia Barcelona, en el mes de marzo de esı angitalizado por Biblioteca Universidad Centroamericana José Simeón Cañas 
cada díal. Y adultos que pierden la vida, como consecuencia de la desnutrición, son, por lo menos, otros tantos. O sea, la economía está "organizada" de tal manera que produce, cada veinticuatro horas, por lo menos 70,000 muertos. Que yo sepa, no ha habido guerra que se acerque, ni de lejos, a semejante crueldad. Y lo peor es que estas cifras van en aumento. Porque cada año que pasa hay más pobres, que son cada vez más pobres.

En efecto, según el Informe sobre desarrollo humano 1996, de Naciones Unidas, el fenómeno más importante, que se está produciendo en la economía mundial, es la creciente concentración de la riqueza en menos paises $y$, dentro de esos países, progresivamente en menos personas. De manera que la distancia, entre ricos y pobres, es cada año mayor. Los datos son conocidos. El 20 por ciento de la población mundial consume el 85 por ciento de la riqueza que produce el planeta. Lo cual quiere decir que el 80 por ciento de los habitantes de la tierra se tiene que contentar con el 15 por ciento de los bienes que se producen en todo el mundo. Y repilo, son dalos de Naciones Unidas, tal como estaban las cosas en 1996. Hoy, seguramente, están peor.

¿Puede tener futuro un mundo así? ¿Puede tener buena conciencia una Iglesia que se remite a Jesús y que vive tranquila en una "organización" mundial que produce tanta muerte y tanto sufrimiento? Si la Iglesia dice que ella representa a Jesús y su evangelio en el mundo, ¿qué liene que decir ante esta situación? ¿Qué dice, de hecho? Y sobre todo, ¿qué hace? Son preguntas que se le ocurren a cualquiera. Pero preguntas que van, no sólo desde la Iglesia a los pobres, sino, sobre todo, desde los pobres a la Iglesia.

Por ejemplo, ¿qué problemas plantean los pobres a la Iglesia? ¿Cómo tendría que organizarse y funcionar la lglesia, si es que realmente está dispuesta a responder, con honestidad y coherencia, a lo que está pasando en el mundo ahora mismo?

Hablar de los pobres y la Iglesia no es, pues, "una cuestión de tantas". Es, sin duda alguna, la cuestión más urgente y más profunda que se plantea a la Iglesia y, por tanto, a los cristianos.

\subsection{Dos precisiones importantes}

Antes de entrar a fondo en el problema, hay que decir dos cosas. Que tienen que quedar muy claras, por honestidad y por justicia.

La primera es que en la Iglesia siempre ha habido y sigue habiendo muchas, muchísimas, personas, grupos, instituciones, organismos de toda índole y procedencia, que no sólo se han preocupado por los pobres, sino, sobre todo,

1. Cfr. R. Castel, Les metamorphoses de la question sociale, París 1995. Citado por J. García Roca, “La globalización entre cl idolo y la promesa", Exodo, 39 (1997), 38.

Digitalizado por Biblioteca "P. Florentino Idoate, S.J."

Universidad Centroamericana José Simeón Cañas 
que han entregado su vida entera a defender a los últimos de la historia, jugándose sus bienes más queridos, su instalación, su prestigio, su seguridad, todo lo que un ser humano se puede jugar en este mundo2.

En la actualidad, concretamente, son heroicos tantos sacerdotes, religiosas y religiosos, voluntarios seglares, organizaciones no gubernamentales, gentes de diversas creencias y colores, que se sienten impulsados por la creciente fuerza de solidaridad, que impregna progresivamente el tejido social en amplios sectores de nuestras culturas, pueblos $e$ iglesias.

Y la segunda es que la autoridad eclesiástica, desde hace más de un siglo, ha venido elaborando una "doctrina social" que, sobre todo en los últimos treinta años, ha alcanzado formulaciones acertadas y fuertes, en defensa de los pobres: sus derechos, sus libertades, su dignidad, reclamando reformas profundas en la economía mundial y denunciando los constantes atropellos que se cometen contra los seres más indefensos de este mundo3. Además - y sobre todo- está la constante predicación del evangelio, que la Iglesia hace en el mundo entero, desde sus publicaciones más estrictamente científicas hasta las homilías y catequesis que cada semana escuchan miles y miles de personas, en casi todos los rincones de la tierra.

Estos dos hechos son así. Y, sin embargo, hay razones muy fuertes que obligan a preguntarse: ¿liene la Iglesia resuelto el problema de lo que significa y exige su relación con los pobres?

¿Por qué esta pregunta? Porque hay síntomas, bastante claros, que hacen sospechar. Incluso que obligan a sospechar. A sospechar, ¿qué? Que en esto de la relación de la Iglesia con los pobres hay algo muy serio, muy profundo, sin resolver.

Comencemos analizando esos síntomas.

\section{Síntomas que hacen pensar}

Estos síntomas se notan en cuanto se plantean preguntas, a primera vista, muy simples. Preguntas que a algunos les pueden parecer ingenuas. $Y$ que a otros, sin duda alguna, les resultarán extrañas, seguramente desconcertantes o incluso francamente molestas. Estas preguntas, concretamente, son cuatro.

¿Qué relaciones concretas mantiene, de hecho, la institución eclesiástica con los poderes que son, en la práctica, los responsables más determinantes de

2. Por poco que scpamos de historia de la Iglesia, sabemos que ha sido asf. Para convencerse de ello, basta leer la excelente recopilación de textos que ha hecho J. I. González Faus, Vicarios de Crisio, Madrid, 1991.

3. Un buen resumen, histórico y analítico de esta enseñanza del magisterio eclesiástico, se puede encontrar en el amplio estudio de l. Camacho, Doctrina social de la Iglesia, Madrid, 1994. 
la organización económica actual? ¿Qué lugar ocupan los pobres en la Iglesia? ¿Qué influencia tienen los pobres en la Iglesia? Pero hay más. Seguramente lo que más nos tendría que hacer pensar, tal como están las cosas, es que, por lo visto, para no pocas gentes del "mundo eclesiástico", los pobres son vistos como un peligro para la Iglesia

\subsection{Institución eclesí́stica y organización económica}

Las autoridades eclesiásticas dicen, en sus predicaciones y escritos, que la Iglesia, de acuerdo con las enseñanzas del evangelio, quiere y exige justicia para los pobres, igualdad de derechos para todos los ciudadanos, libertad para los que carecen de liberlad. Es innegable que eso se dice. Pero, ¿qué es lo que se hace? Todo el mundo sabe que la instilución eclesiáslica procura, por todos los medios a su alcance, mantener buenas relaciones con los poderes políticos, en casi todos los países. No sólo en los países en donde se respetan los derechos humanos, sino también en donde esos derechos se ven atropellados.

En la televisión hemos visto a altísimos dignatarios eclesiásticos dando la comunión públicamente a dictadores que tienen las manos manchadas con mucha sangre inocente. Más en concreto: para nadie es un secreto que la diplomacia vaticana se entiende, lo mejor que puede, con los gobiemos más influyentes en la política y en la economía mundial. Y eso, claro está, tiene que llevar consigo callarse cierlas cosas, disimular otras, ceder en esto o en lo otro. El hecho es que hay países que nadan en la abundancia. $Y$ hay otros que se mueren en la miseria. Pero resulta que las autoridades eclesiásticas se llevan bien con todos. $\mathrm{Y}$ en todas partes se aplaude al papa y se lo recibe con los más altos honores.

Por poner un único ejemplo reciente y bien doloroso. El Vaticano fue el único Estado del mundo que reconoció al gobierno militar que derrocó, mediante un golpe de Estado, al presidente de Haití, J. P. Aristide, elegido democráticamente. Tal reconocimiento no fue sólo un "desliz" diplomático, sino una acción contraria al evangelio. Y este juicio es independiente del juicio que puede merecer Aristide (y que hoy en día no podría ser posilivo). La prueba de ello es que los otros eslados del mundo eran aún más recelosos y más enemigos de Aristide que el Vaticano. Pero se abstuvieron de reconocer a los golpistas por un elemental respeto formal a los principios de democracia y no-violencia.

Realmente, si la cosa se piensa fríamente, ¿no es para sospechar (sospechar, al menos) que en todo esto ocurre algo muy raro? ¿Cómo es posible que quien grita en defensa de los pobres sea aclamado por aquellos que son los responsables más directos de que en este mundo haya tantos pobres? ¿Qué pasa en la Iglesia para que todo esto, no solamente ocurra así, sino que además la mayor parte de la gente lo vea como la cosa más natural del mundo? 


\section{2. ¿Qué lugar ocupan los pobres en la Iglesia?}

En teoría, la respuesta es clara. Los pobres son, para la lglesia, lo que fueron para Jesús: los preferidos, los más importantes, los primeros. Pero eso es en teoría. Porque en la práctica, todos sabemos que, con frecuencia, las cosas funcionan de otra manera.

En eslo hay que procurar ser muy concretos, si es que de verdad queremos hablar, no de teorías, sino de lo que realmente pasa en la vida. Por ejemplo, ¿qué lugar ocupan los pobres, tantas veces, en las ceremonias eclesiásticas? Seguramente están pidiendo limosna en la puerta del templo. Desde luego, no suelen estar en los primeros puestos. Y menos aún en el presbiterio. ¿Qué harían allí? Estorbar. ¿Qué lugar ocupan en las reuniones o en los encuentros eclesiales? ¿Qué lugar se les concede en los proyectos pastorales, en los sínodos diocesanos o, más que nada, en los alıos dicasterios de la curia romana?

Sin duda alguna, muchos de los que lean esto pensarán que estas preguntas no son sino tonterías o radicalismos sin pies ni cabeza. No pensaban así los cristianos, en los primeros tiempos de la Iglesia. Lo del lugar, que cada cual ocupa o prelende ocupar, era un asunto muy serio y que dio mucho que hablar entre aquellos cristianos. La carta de Santiago denuncia severamente a los que sientan a los pobres en peor lugar que a los ricos (Sant 2, 1-4). Y en los evangelios, Jesús rechaza, con palabras durísimas, a los que pretenden situarse los primeros (Mc 10, 37; Mt 20, 21; Mc 9, 35; 12, 38-39; Lc 20, 46), porque en eso consistía una de las pretensiones preferidas por los fariseos (Lc 11, 43). Todo lo contrario: en la comunidad cristiana, la tendencia dominante tiene que ser irse derecho al último silio (LC 14, 7-11) o estar en el banquete, no sentado cómodamente, sino sirviendo a los demás (Lc 22, 27).

Digamos, pues, como mínimo, que si eso es hoy inviable, hay que procurar ir haciéndolo viable: porque lo del lugar, que a cada cual le corresponde, no es ninguna lontería. En todas las sociedades, instituciones, grupos, el lugar que se ocupa expresa el rango de la persona, la estima que merece, el poder que tiene. $\mathrm{Y}$ eso es lo que dio tantos quebraderos de cabeza a Jesús y sus discípulos. Porque Jesús quiso, a toda costa, cambiar el orden que nosotros hemos puesto, según nuestras conveniencias. Para Jesús, "los últimos, los primeros; y los primeros, los últimos" (Mt 20, 16).

Pero está visto que esta subversión radical no nos entra en la cabeza. Lo de Jesús duró algún tiempo en la Iglesia. A comienzos del siglo tercero, la Didaskalía (un directorio litúrgico y canónico de primera importancia) manda que, cuando la comunidad eclesial está reunida y no queda ni un asiento libre, si entra un pobre, que el obispo se levante de su sede, que se coloque allí el mendigo y que el obispo se siente en el suelo4. Naluralmente, un radicalismo

4. Didaskalia, II, 58 (ed. Funk, pp. 168-170)

Digitalizado por Biblioteca "P. Florentino Idoate, S.J."

Universidad Centroamericana José Simeón Cañas 
así, no pudo durar mucho tiempo en la Iglesia, sobre todo tal como la Iglesia se organizó, a partir del siglo cuarto. Los pobres volvieron a su sitio, el último. Y los notables recuperaron su lugar preferente. ¿No hace esto sospechar (por lo menos, sospechar) que aquí tenemos un síntoma de los que tocan fondo?

\section{3. ¿Qué influencia tienen los pobres en la Iglesia?}

Aquí hablamos de una cosa bastante obvia: lo que se suele llamar una persona "influyente". Por ejemplo, cuando hay que pedir un favor a un obispo, a un nuncio o al Vaticano, ¿echamos mano de un pobre, porque sabemos que eso no falla? ¡Qué tontería! Eso es lo malo. Ahí está el síntoma preocupante. Que eso nos parezca una tontería, $i$ no es para sospechar que en la Iglesia hay cosas que están más lejos del evangelio de lo que seguramente nos imaginamos? Pues se dice y se repite que los pobres son nuestros mejores intercesores y lienen gran influencia en el cielo. ¿Por qué no en la tierra, si la Iglesia debe "anticipar" el cielo?

Esto necesita alguna explicación. Porque el asunto es más hondo de lo que parece. En esta vida, una persona tiene influencia de verdad, si realmente su intervención resulta (más o menos) decisiva, es decir, si condiciona o determina (de la manera que sea) las decisiones que se toman, ya sea en una asamblea, en una institución, en un grupo, etc.

Esto supuesto, a cualquiera se le ocurren algunas preguntas. Ante todo, la más elemental, la más genérica: ¿qué influencia tienen los pobres en las decisiones importantes que se toman en la Iglesia?, ¿se les consulta, en este sentido?, ¿se tiene en cuenta su punto de vista?, ¿se piensa siquiera que semejante punto de vista puede ser importante?, ¿se llama a los pobres para que opinen cuando se trae entre manos un asunto de cierta envergadura? Viniendo a cosas más concretas: ipueden, de hecho, opinar los pobres cuando se trata de nombrar a un párroco, de designar a un obispo o, más simplemente, de montar o desmontar tal o cual institución que a ellos les afecta para bien o para mal?

Si los párrocos se quejan de que no suelen tener corresponsabilidad en el gobiemo de las diócesis; si los laicos, en general, no tienen poder decisorio alguno en los asuntos eclesiásticos, ¿qué influencia real de decisión van a tener, en esta lglesia nuestra, las pobres gentes, que ni saben de estas cosas, ni les suelen interesar estas cosas, porque la pura verdad es que son cosas que les resultan extrañas, lejanas y seguramente sin sentido?

Pero, por encima de todo lo anterior, hay algo que es, sin duda, lo más sintomático. ¿Qué influencia tienen los pobres, no ya en las decisiones de la Iglesia, sino, sobre todo, en el pensamiento que se enseña y hasta se impone a los creyentes? Dicho más claramente, ¿qué influencia tienen los pobres en la leología? Es decir, ¿influyen los pobres en la manera de entender a Dios, de

Digitalizado por Biblioteca "P. Florentino Idoate, S.J."

Universidad Centroamericana José Simeón Cañas 
interpretar el evangelio, de explicar en qué consiste la salvación cristiana, etc., etc.?

Aquí, otra vez, habrá quien piense que a qué vienen este tipo de preguntas. ¿Qué saben los pobres de teología?, ¿qué pinlarían los pobres en un congreso de teólogos? Y sin embargo, con el evangelio en las manos, no hay más remedio que tomar en serio estas cuestiones, por más impertinentes que resulten. En efecto, Jesús dijo un día, de manera categórica y desconcertante, que el Padre, Señor del cielo y de la tierra, "oculta" (ékrypsas) lo más profundo que hay en éls a ciertas personas, mientras que se "lo da a conocer" (apekálypsas) a otras (Mt 11, 25).

Ahora bien, lo sorprendente es que, según Jesús, los que no se enteran del asunto de Dios son los "sabios y entendidos", mientras que quienes lo comprenden son, literalmente hablando, "los que no tienen nada que decir", ya que eso, ni más ni menos, significa el término que utiliza el evangelio: nepioí. Habría que estar ciegos para no darse cuenta de que, en realidad, lo que Jesús hace, al decir lo que acabo de indicar, es poner radicalmente en cuestión nuestra teología. Porque la pura verdad es que la teología que se hace en la Iglesia es la que elaboramos los que nos consideramos sabios y entendidos, mientras que, en esta manera de pensar y de hablar, siguen sin tener nada que decir los nepioi, o sea, los que, según Jesús, entienden del asunto.

En el fondo, se trata de comprender que el Dios, que se revela en Jesús, es un Dios que no se alcanza ni por el esfuerzo humano, ni por el estudio, ni por la especulación de los hombres más geniales. Eslo se ha dicho así, por lo menos, desde los tiempos de san Aguslín. Lo que pasa es que eso se redujo a "pura teología", es decir, a pura teoría. Y su expresión concreta consistió en el tratado de la gracia, una realidad "sobre-natural", que está por encima de lo histórico, lo sociológico, lo económico, lo cultural, todo lo de este mundo. Y así resultó el "saber teológico", que siempre contó con la gracia de Dios (eso por supuesto)?, pero que, a la hora de la verdad, era y sigue siendo el saber de los "sabios y entendidos".

Sin embargo, Jesús no planteó así este problema. En el evangelio, lo "teológico" y lo "sociológico" se funden y se confunden hasta desconcertar a los que "sabemos y entendemos". Por eso, san Pablo (que debía saber de estas cosas

5. Que se refiere al conocimiento profundo del Padre y a la revelación que del Padre hace Jesús, nos consı por lo que dice en el v. 27, donde vuelve a utilizar exactamente el mismo verbo (apokalypsai).

6. Por eso, el término nepios se suele traducir por "niño" o "pequeño". En realidad, es $n \hat{e}$-epos, o sea in-fans, el que no habla. Cfr. M. Zerwick, Analysis Philologica Novi Testamenti Graeci, p. 28.

7. Y con eso la leología se convenció a sí misma de que ella era el "saber de Dios", no un saber de esle mundo. 
más que nosotros) se atreve a formular todo este asunto de una manera descarada y provocativa. La afirmación de Pablo resulta asombrosa: "cuando Dios mostró su saber, el mundo no reconoció a Dios a través del saber" (1Cor 1, 21).

¿Qué quiere decir esto? Se refiere al "fracaso" en que acaba lo de Dios cuando se intenta alcanzar a través de "las persuasivas palabras de la sabiduría humana" (1Cor 2,4). Porque, como se ha dicho muy bien, aunque los hombres tenían la posibilidad de conocer a Dios por "su eterno poder y su divinidad" (Rom 1, 20), ese lipo de conocimiento desembocó en un fracaso: su conocimiento se redujo a una ciencia muerta, que incluso degeneró en una vergonzosa idolatría (Rom 1, 21-23)8. "Por eso Dios tuvo a bien salvar a los que creen con esa locura que predicamos" (1Cor 1,21). Así, Dios arrumbó lo del "poder" y echó por el camino de la "debilidad" (1Cor 1,25). Esta es la "teología" que explica Pablo.

Pero lo delerminante ahora es caer en la cuenta que esla "teología" se hizo vida, se hizo historia, en un "hecho sociológico" desconcertante. El mismo Pablo lo explica sin rodeos: " $A$ A ver un sabio, a ver un letrado, a ver un estudioso del mundo éste!" (1Cor 1, 20). Pablo también desautoriza a los sabios y entendidos. Entonces, ¿quiénes son los que entienden de las cosas de Dios? Parece que no son ni los "intelectuales", ni los "poderosos", ni la gente de "buena familia" (1Cor 1,26). Y para que no queden dudas, a continuación san Pablo da la lista: "lo necio del mundo se lo escogió Dios para humillar a los sabios; y lo débil del mundo se lo escogió Dios para humillar a lo fuerte; y lo plebeyo del mundo, lo despreciado, se lo escogió Dios: lo que no existe, para anular a lo que existe" (1Cor 1, 27-28). Más abajo no se puede llegar.

Pues bien, según Jesús y según san Pablo, es desde abajo desde donde únicamente se puede conocer, comprender y asimilar a Dios y todo lo que se refiere a Dios. Está visto que los pobres tienen la palabra decisiva o son el factor decisivo en lo que debe ser el núcleo central del pensamiento de la Iglesia. Si es que la Iglesia esı́́ realmente decidida a ser fiel a Jesús. Lo cual, dicho de otra manera, equivale a afimnar que, en el magisterio de la Iglesia, los pobres tienen siempre que decir alguna palabra, que, nos guste o no, es y será siempre decisiva. Por lo tanto, el problema fundamental, para la Iglesia, no es sólo evangelizar a los pobres, sino dejarse evangelizar por ellos.

Este tercer síntoma es, si cabe, más preocupante que los anteriores. Porque si todo lo que acabamos de recordar (desde el evangelio de Mateo hasta la Primera Carta a los Corintios) es cierto, la pregunta inevitable es: el saber sobre Dios, la

8. O. Kuss, Cartas a los corintios, Barcelona, 1976, p. 192; cfr. W. Schrage, Der erste Brief an die Korinther, en Evangelisch-Katholischer Kommentar zum Neuen Testament. IV/1, Zürich, 1991, p. 178.

Digitalizado por Biblioteca "P. Florentino Idoate, S.J."

Universidad Centroamericana José Simeón Cañas 
teología, ies algo resuelto en la Iglesia? Desde el momento en que los pobres no han tenido, ni tienen nada que decir sobre este asunto, ino nos hemos privado de la fuente más determinante del conocimiento y de la comprensión del evangelio?

\section{4. ¿Los pobres vistos como un peligro para la Iglesia?}

Pero hay más. Seguramente, lo que más nos tendría que hacer pensar, tal como están las cosas, es que, por lo visto, para no pocas gentes del "mundo eclesiástico", los pobres son vistos como un peligro para la Iglesia.

Al decir esto, no se trata ni de una exageración provocativa, ni de sacar las cosas de quicio. Los hechos están a la vista de todo el mundo.

Durante siglos, los pobres han sido objeto de ayuda y limosna en la Iglesia. Pero nunca habían sido sujeto de decisiones y de pensamiento entre los eclesiásticos y para los eclesiásticos. Ahora bien, en los últimos treinta años se ha producido el cambio. Primero, Juan XXIII empezo a hablar de la "Iglesia de los pobres". Aquello ya no gustó a algunos y sabemos que hubo profesores de eclesiología que se reían (literalmente) de esa expresión. Luego vinieron la "leología de la esperanza" (Moltmann), la "teología polílica" (Metz) y las "cristologías ascendentes", que afirmaron decididamente que la salvación cristiana se hace presente en la historia, en la sociedad. Y dijeron, nada más y nada menos, que la cristología es indisociable de la soteriología o, en otras palabras, que la cristología se constituye soteriológicamente (W. Kasper), lo cual quiere decir, entre otras cosas, que Jesús "fue constituido Hijo de Dios... por su resurrección de la muerte" (Rom 1,4). Pero sabemos que la muerte y la resurrección presuponen la vida que llevó y no se pueden disociar de esa vida (cfr. Rom 1, 3): la vida de un pobre, que nació y vivió entre los pobres.

$Y$ esto es lo que ya resultó desagradable y seguramente hasta molesto, para algunas personas. Porque un Jesús, que viene del cielo, es admirable, sublime y todo lo que se quiera. Pero un Jesús, que viene de los pobres, ni admira ni sublima, sino que probablemente inquieta $y$, en cualquier caso, plantea muchos interrogantes.

Por ahí empezó el peligro, para ciertos espíritus y para algunas "gentes de Iglesia". Pero la cosa se terminó de complicar cuando, allá por los primeros años setenta, apareció una teología que puso a los pobres justamente en el centro mismo de sus preocupaciones, de sus problemas y de las soluciones.

Lo que pasó entonces, y en los años siguientes, es algo que (por más vueltas que se le dé) resulta difícil de explicar. Por una razón: durante siglos, muchos

9. Por ejemplo, una enciclopedia, por lo demás valiosísima, como es Sacramentum Mundi, habla de los "peligros" que entraña esta expresión. Cfr. Vol. V, p. 483.

Digitalizado por Biblioteca "P. Florentino Idoate, S.J."

Universidad Centroamericana José Simeón Cañas 
siglos, la leología no se ocupó de los pobres nada más que para medir la cantidad de limosna, que los ricos tenían que dar a los necesitados, a fin de que los ricos se quedaran tranquilos en su conciencia; o para exhortar a los pudientes a ser generosos con los desgraciados de esta vida.

Y, siendo así que el evangelio da tanta importancia a los pobres, nadie se preguntó si los pobres tenían que decir algo más en la teología y en la Iglesia. Esto ya es extraño. Pero, en fin, pase. Ahora, lo que difícilmente cabe en la cabeza es que, cuando por primera vez en la historia, una teología se atreve a decir que los pobres tienen una palabra decisiva en el asunto de Dios, cuando se afirma que los pobres tienen que ser oídos, de manera que desde ellos hay que repensar el saber teológico, entonces se organiza el gran escándalo, en no pocos ambientes eclesiásticos: el Vaticano preocupado, obispos asegurando que esa teología divide a la Iglesia, teólogos disparando sus baterías más pesadas contra lo que consideran la perversión mayor de la teología, iqué sé yo! Sin duda alguna, la corta historia de la teología de la liberación es la prueba más patente de que para muchos "hombres de Iglesia" los pobres son un verdadero peligro, cuando los pobres se toman en serio y con todas sus consecuencias.

Efectivamente, las cuatro preguntas planteadas confirman la sospecha: hablar de los pobres y la Iglesia (o mejor, del desafio de los pobres a la Iglesia) es hablar de un problema más hondo de lo que algunos se imaginan. Lo que interesa ahora es delimitar el problema.

\section{Delimitación del problema}

Que nadie se inquiete pensando que aquí vamos a poner en cuestión los dogmas de la Iglesia. Primero, porque si queremos vivir en comunión de fe con la Iglesia, no podemos echar por la borda sus dogmas. Segundo, porque si la Iglesia no tiene debidamente resuelto el problema de su relación con los pobres, eso no se debe a cuestión dogmálica alguna. Los problemas que nos plantean los pobres no tienen su raiz primordialmente en las ideas, sino en la sensibilidad de las personas. $O$ dicho de otra manera, estar o no estar de parte de los pobres, no es cuestión que depende, ante todo, de tener o no tener tales o cuales ideas en la cabeza, sino de ser o no ser sensibles al sufrimiento de los débiles.

\subsection{No es un problema dogmático}

Esto necesita alguna explicación. Antes que nada, nunca deberíamos olvidar que la "mentalidad clerical" suele distinguirse, entre otras cosas, por ser una "mentalidad dogmática". Los "hombres de Iglesia" estamos acostumbrados a pensar que las "afirmaciones doctrinales" tienen más importancia de la que realmente tienen. $\mathrm{Y}$ así, unos (de orientación conservadora) se imaginan que, afirmando tales o cuales verdades, se resuelven los problemas que plantea la vida. Mientras que otros (de orientación renovadora) se imaginan también que Digitalizado por Biblioteca "P. Florentino Idoate, S.J."

Universidad Centroamericana José Simeón Cañas 
negando esas mismas verdades es como la vida estará debidamente resuelta. Sin duda, unos y otros tienen parte de razón. Pero es sólo una parte. Una parte pequeña. Porque la vida es indeciblemente más compleja que las ideas. Y de sobra sabemos que, con relativa frecuencia, personas con ideas excelentes cometen atropellos impensables contra personas concretas.

Más concretamente, como enseguida veremos, el problema que interfiere, en gran medida, la correcta relación de la Iglesia con los pobres, es el problema del poder. Pero eso no se refiere, para nada, a las cuestiones dogmáticas, que, de una manera o de otra, se relacionan con la apostolicidad de la Iglesia, la sucesión apostólica, la jerarquía eclesiáslica y la autoridad que compete a la jerarquía.

O dicho más claramente, el problema de los pobres y la Iglesia no depende de la autoridad que hay (y tiene que haber) en la Iglesia, sino del modo como se ejerce esa autoridad. Por una razón que se comprende enseguida: en la práctica, se confunde el origen de la autoridad con la extensión de esa autoridad. De donde resulta que, si el origen es divino (la autoridad viene de Dios), la extensión es ilimitada (¿quién va a poner límites a una autoridad divina?). Y eso se traduce en un modo de ejercer el poder, cuyo centro está es el poder mismo y no en aquellos a quienes el poder tiene que servir.

Desde el momento en que las cosas funcionan así (por más que nunca se argumenten de esta manera), el poder en la Iglesia se hipertrofia. Con las consecuencias que después veremos. Pero esto ya no es un asunto dogmático, es decir, no es una cuestión de verdades y de ideas. Es un fenómeno que adentra sus raíces mucho más en el fondo de lo que somos las personas. Exactamente, en la sensibilidad de cada uno. Porque todo depende de que la sensibilidad esté orientada hacia el poder o hacia el sufrimiento de los débiles. Por poner un ejemplo, sin duda alguna, Inocencio III y Francisco de Asís profesaban el mismo "credo", las "verdades de fe" del uno y el otro eran las mismas. Pero Inocencio III no tenía bastante con llamarse "vicario de Pedro" y empeź́ a llamarse "vicario de Crislo", mientras que Francisco de Asís decía que cuando se encontraba con un hombre más pobre que él se consideraba un ladrón. No es cuestión de "dogmas", es cuestión de "sensibilidad".

\subsection{Tampoco es un problema meramente económico}

Si hablamos de pobres, es que estamos hablando de un asunto de dinero, concretamente de gente que carece de los medios económicos indispensables para vivir. Y eso es verdad. Pero sólo una verdad a medias. Porque el dinero, con ser tan importante, no es todo en la vida. Por eso, desde ahora, hay que dejar bien claro que el problema que plantea la relación entre los pobres y la Iglesia no se sitúa simplemente al nivel de lo económico. Es algo que adentra sus raíces más abajo, en el fondo mismo de la existencia humana. Y esto, 
seguramente, es lo que algunos no han acabado de entender, tanto en el caso de determinados defensores de la teología de la liberación, como en el extremo opuesto, entre los que han atacado esa teología sin tino y sin mesura.

La cosa se comprende desde el momento en que nos damos cuenta de este hecho: en los evangelios aparecen claramente cualro grupos de personas con los que Jesús se solidariza, hasta el extremo de jugarse su prestigio, su fama, su seguridad y su vida por defender a tales personas. Aparecen también, en sentido opueslo, otros cuatro grupos de personas con los que Jesús se enfrenta hasta tal punto que aquello le costó la vida. Los cuatro grupos, con los que Jesús se solidariza, son los enfermos, los pobres, los publicanos (con los pecadores) y las mujeres. Los cuatro con los que se enfrenta son los fariseos, los escribas (letrados), los sacerdoles y los ancianos (senadores).

Es verdad que en la sociedad judía del tiempo de Jesús había otros grupos suficientemente definidos. Ante todo, los saduceos, que eran el partido ideológico opuesto a los fariseos, pero que, en la práctica, se identificaban con los sumos sacerdotes y los senadores o ancianos. Es decir, tanto la aristocracia sacerdotal como la nobleza laica pertenecían al partido saduceo, entre otras cosas porque era el partido de ideas más liberales y más tolerante en materia religiosa 10. Por otra parte, estaban los revolucionarios políticos (más tarde se les llamó "zelotas"), que luchaban por liberar al pueblo judío de la opresión de los romanos 11 . Al margen de unos y otros se situaban los esenios, que pensaban encontrar a Dios, retirándose al desierto a orar y hacer penitencia 12. De estos tres últimos grupos, los evangelios hablan en contadas ocasiones. Por eso nos vamos a fijar en los otros ocho (cuatro de una parte y cuatro de otra), que centran la trama de lo que fue la existencia pública de Jesús: su vida conflicliva y su muerte violenta.

10. Las diferencias ideológicas entre fariseos y saduceos eran cuatro. Los saduceos, en primer lugar, se atenían a la Torá (ley) escrita y no aceplaban las tradiciones posteriores. Segundo, no aceplaban la fe en la resurrección de los muertos. Tercero, negaban la existencia de los ángeles. Cuarto, afirmaban que Dios no ejerce inllujo alguno sobre las acciones humanas. Cfr. E. Schürer, Historia del pueblo judio en riempos de Jesús, Vol. Il, Madrid, 1985, pp. 510-513.

11. Es claro que Jesús se relacionó con los movimientos revolucionarios de su liempo, como consta por sus discípulos: Simón, al que apodaban el "zelota" (Lc 6, 15; Hech $1,13)$ y Judas que, según parece, pertenecía a los "sicarios", la facción más violenta de los revolucionarios. Incluso se ha dicho que Pedro y Andrés estaban vinculados con tales movimientos subversivos. Cfr. S. Brandon, Jesus and the Zelots, Manchester, 1967, que pretendió defender que el mismo Jesús fue zelota. Precisiones sobre esta lesis: G. Baumbach, "Zeloten und Sikarier", ThLZ 90, 1965, pp. 727-740; Id., "Die Zeloten", BuL 41, 1968, pp. 2-19; M. Smith, "Zelots and Sikarii. Their origins and relation", $H T h R$ 1, 1971, pp. 1-20.

12. Sobre los esenios, cfr. el reciente estudio de H. Stegemann, Los esenios. Qumrán, Juan Bautista y Jesús, Madrid, 1996.

Digitalizado por Biblioteca "P. Florentino Idoate, S.J."

Universidad Centroamericana José Simeón Cañas 
Ahora bien, lo importante aquí es responder a esta pregunta: ¿qué tenian en común los cuatro grupos con los que se solidarizó Jesús y qué tenian en común los cuatro con los que se enfrentó? Planteada así la cuestión, la respuesta es clara: lo que tenían en común unos y otros no era un asunto de dinero. Porque ni los cuatro, con los que se solidarizó, eran pobres; ni los cuatro, con los que se enfrentó, eran ricos. Entre los publicanos había de lodo, y los evangelios parecen distinguir entre los "jefes de publicanos" (architelones: cfr. Le 19, 2), que serian propietarios de varios puestos de control, y muy ricos como Zaqueo, y los simples recaudadores (telones: cfr. Lc 5, 27), subarrendados en algún puesto, y cuya situación era mucho más variada. Esto explicaría la diferente reacción de Zaqueo ("dar la mitad", "devolver el cuádruplo") y de Leví ante la llamada del Señor. Pero, en cualquier caso, sigue en pie que Jesús mantuvo buenas relaciones con muchos de estos hombres 13 , que manejaban tanto dinero, frecuentemente mal adquirido (porque las normas sobre impueslos eran imprecisas y mal conocidas por el pueblo, lo cual se prestaba a extorsiones y abusos) ${ }^{14}$. Además, esos impuestos eran muchas veces para los romanos, o sea, eran colaboracionistas con el poder opresor, lo que llevaba consigo el desprecio y el odio generalizados 15 . Por eso, los publicanos o recaudadores eran los más marginados entre los marginados de aquella sociedad.

En contraste con esta actitud, sabemos también que Jesús se enfrentó fuertemente con los escribas y con los fariseos, de los que nos consta que, aunque algunos pudieran ser ricos (como el que invita a Jesús según $L c 7,36 s s$ ), había entre ellos mucha gente pobre, cosa que está sobradamente atestiguada por la documentación que tenemos de aquel tiempo ${ }^{16}$. Los escribas o doctores de la ley tenian prohibido cobrar por su oficio y vivían, en parte, de oficios de escasa reputación, o también de limosnas que recibían 17. Y de los fariseos nos consta

13. Jesús admite a un publicano entre sus discipulos (Mi 9, 9 par) y se seinla a la mesa con los publicanos (Mt 9, 10 par), lo que es motivo de escándalo ( $M ! 9,11$ par), ya que, en la cultura de aquel tiempo, comer con alguien era lo mismo que solidarizarse con él. Cfr. J. Jeremias, Jesus als Weltvollender, Güllersloh, 1930, pp. 74-79; 0. Holius, Jesus Tïschgemeinschaft mit den Sündern, Stuttgart, 1967, p. 11 ss. De ahi que Jesús es acusado de ser amigo de publicanos y pecadores (Mi 11, 19), puesto que los publicanos convivian con él (Lc 18,1). Además, Jesús presenta al publicano como el hombre al que Dios acepta (Le 18, 10-13) y no duda en alojarse en casa de un publicano (Le 19, 2-8). Sobre la comida como signo de solidaridad, cfr. el excelente estudio de R. Aguirte, La mesa compartida. Estudios del N.T. desde las ciencias sociales, Santander, 1994, pp. 17-133.

14. Cfr. J. R. Donahue, "Tax Collectors and Sinners: An Attempt at Identification", The Catholic Biblical Quarterly 33, 1971, pp. 39-61; J. A. Filzmyer, El evangelio de Lucos, Vol. II, Madrid, 1987, pp. 330-331.

15. Excelente análisis de esle asunto, en J. Jeremias, Jerusalén en tiempos de Jesús, Madrid, 1977, pp. 316 y 322-323.

16. Cfr. W. Grundmann, "Los judios de Palestina entre el levantamiento de los Macabeos y el fin de la guerra judía", en J. Leipold y w. Grundmann, El mundo del Nuevo Testamento, Vol. l, Madrid, 1973, p. 203.

17. Cfr. J. Jeremias, Jerusalén en tiempos de Jesús, pp. 131-133.

Digitalizado por Biblioteca "P. Florentino Idoate, S.J."

Universidad Centroamericana José Simeón Cañas 
que no se contaban entre la clase superior, sino que eran gentes del pueblo sin formación de escribas'18.

Por lo tanto, lo que había en común, en los cualro grupos con los que se solidarizó Jesús, no era simplemente la pobreza económica. La solidaridad con los enfermos era cercanía lo mismo a mendigos (Le 18, 35ss) que a gente de buena posición social (Mc 5, 35ss par; Jn 4, 46-54; 11, 1-44), aunque el hecho de considerar a muchos enfermos como impuros solía llevar a su marginación social. Y en el caso de las mujeres, a las que siempre defiende Jesús, aun cuando fueran personas de mala reputación, sabemos que algunas de las que lo acompañaban eran gente notable (Lc 8, 3) o que podía hacer gastos que escandalizaban (Jn 12, 3-5).

Y de la misma manera podemos decir que lo que unía a los cuatro grupos, con los que se enfrentó el mismo Jesús, no fue su condición económica prepotente, ni siquiera desahogada. Por supuesto, tiene que quedar muy claro que Jesús denunció con vigor los peligros de la riqueza, porque es una auténtica idolatría (Mt 6, 19-21.24; Lc 6, 24; 16, 11-12), incapacita para entrar en el rejno de Dios (Mt 19, 24 par) y hace imposible la salvación (Mt 13, 22; Lc 16, 19 31). Pero, sin duda alguna, hay algo que, para la mentalidad de Jesús, es más peligroso que el dinero. Porque en ese "algo" reside la raíz de la peligrosidad del dinero.

Lo cual quiere decir que, según el evangelio, la raíz más honda del daño que los hombres nos causamos unos a olros, no se sitúa ni sólo ni principalmente a nivel económico. El dinero es un factor decisivo en la tragedia de los pobres. Eso es evidente. Pero Jesús vio claramente que, en este asunto, intervienen otros factores, que son los últimos delerminantes de la siluación. Concretamente cuando, en tal situación interviene el hecho de la religión. Y ése es justamente el caso que se nos presenta cuando se trata de analizar la relación entre los pobres y la Iglesia. Exactamente lo que estamos intentando hacer aquí.

\subsection{En el fondo de lo condición humana}

Jesús nació en un establo, donde viven las bestias. Y murió en una cruz, donde acababan, en aquel tiempo, los delincuentes más peligrosos e indeseables. Todo esto, ni ocurrió por casualidad, ni es intranscendente para nuestra fe. Porque, a partir de estos hechos, los creyentes en Jesús afirmamos que el ideal de hombre y de vida, que da razón de nuestras convicciones más profundas, es

18. J. Jeremias, op. cit., p. 261. Concretando más, fariseos y escribas pertenecían a la clase de los subaliernos, es decir, a las clases populares, separadas por un "abismo enorme" de los ricos. Así lo ha demostrado A. J. Saldarini, Pharisees, Scribes and Sadducees in Palestinian Society, Edimburgh, 1988, pp. 39-45. Este autor siguc, en este punto, la clasificación anterior de G. E. Lenski, Power and Privilege: $A$ Theory of Social Stratification, New York, 1966.

Digitalizado por Biblioteca "P. Florentino Idoate, S.J."

Universidad Centroamericana José Simeón Cañas 
el ideal que se resume en la existencia de una persona que vivió (desde el principio al fin) en lo marginal de la sociedad. Ahora bien, hablar de marginalidad es hablar de algo que toca fondo en la condición humana. Porque lo peor, que lleva consigo la marginalidad, es la indignidad: carecer de los derechos que otros tienen; y no merecer el respeto que merece toda persona normal. Por eso, la indignidad es lo peor que lleva consigo la pobreza.

O mejor dicho, la indignidad es peor que la pobreza misma. La gente lo suele decir: "pobres, pero honrados". Porque la honra y la dignidad son lo más grave y lo más delicado que se puede perder. $O$ dicho de olra manera, la honra y la dignidad es lo que más apetece todo ser humano.

Más aún, si los seres humanos apetecemos tanto el dinero, no es sólo ni principalmente por las ventajas materiales que proporciona. Las personas y las instituciones apetecen, sobre todo, el dinero por la seguridad, el poder, la influencia, la prepotencia, el "status social", la respetabilidad y, en definitiva, la fuerza de hechizo que ejerce en nuestra sociedad. Marx se equivocó en muchas cosas. Pero hay una en la que acertó plenamente: en el "carácter fetichista" que tiene el capital. Es la mercancía convertida en "fetiche", algo que adquiere un "carácter místico", casi religioso, "una cosa muy compleja, henchida de sutilezas metafísicas y de argucias teológicas"19.

En última instancia, todo esto quiere decir que lo más hondo, en la condición humana no es el deseo de riqueza, sino la apelencia de seguridad, de honor y de poder. Es verdad que lo más urgente es tener los medios necesarios para no morirse de hambre. Pero lo más profundo en el ser humano es "ser como dioses" (cfr. Gen 3, 5), la aspiración de ser y tener sin limites, que no se reduce a lo económico, sino que lo rebasa indeciblemente y lo concentra, sobre todo, en el deseo de poder.

Al decir esto, vendrá bien indicar la distancia cultural tan profunda que existe entre lo que se vive actualmente, en nuestras sociedades industrializadas, $y$ lo que se vivía en la sociedad del tiempo de Jesús. Para decirlo en pocas palabras, la diferencia probablemente más honda, está en que el valor determinante, en nuestra cultura, se centra en torno a la economía, mientras que el valor determinante, en la cultura del tiempo de Jesús, giraba en tomo al honor. Los recientes estudios de antropologia cultural sobre los valores centrales del mundo mediterráneo del siglo primero parecen demostrar, con bastante claridad, que la reivindicación del propio valor, socialmente reconocido, era el valor más apreciado y, por tanto, más influyente en la sociedad en que vivió Jesús²0.

19. K. Marx, El Capital, I. I, cap. 1, IV, ed. Cartago, Buenos Aires, 1973, Vol. l, pp. 86-87.

20. Sobre este asunto, es conocido el reciente estudio de B. J. Malina, El mundo del Nuevo Tesiamento. Perspectivas desde la antropologia cultural, Estella, 1995, especialmente el Capítulo II, pp. 45-83, con bibliografia en pp. 81-83. Importante el volumen editado por D. D. Gilmore, Honor and Shame in the Unity of the 
Ahora bien, a partir de este estado de cosas, se comprende por qué Jesús se solidarizó con los cuatro grupos de personas que, en aquella sociedad, eran exactamente las gentes más marginales del sistema: los más explotados, los más despreciados, incluso (cuando se trataba de los publicanos y pecadores) los más odiados; en cualquier caso, los que no representaban nada ni podían decir nada en aquella cultura. Y por eso también se comprende por qué Jesús se enfrentó con los cuatro grupos que marginaban, despreciaban y odiaban a los anteriores.

\subsection{El factor religioso}

Estamos hablando de los "pobres" y la "Iglesia". Ello implica que estamos hablando de los pobres y la religión. Se trata, por tanto, de comprender cómo el factor religioso incide en la relación con los pobres de una manera muy particular. Algo que mucha gente seguramente no se puede imaginar.

Desde este punto de vista, lo primero, que se debe tener presente, es que la marginación con que se encontró Jesús en la sociedad de su pueblo y de su tiempo era una marginación producida por la religión. Aquí es conveniente recordar algo que todo el mundo sabe, pero que no siempre se tiene en cuenta: las religiones, por lo general, han predicado (de una manera o de olra) el amor al prójimo. Pero no es menos cierto que las religiones, con demasiada frecuencia, han dividido y siguen dividiendo a las personas, a los grupos y a los pueblos, hasta provocar el odio, el enfrentamiento y la muerte. En la sociedad y en el tiempo de Jesús, la religión dividía a la población en dos categorías de personas radicalmente contrapueslas e incluso enfrentadas. Por una parle, estaban los haber, que se consideraban los intachables, los auténticos en materia religiosa; por otra parte, los 'amme haArez, los incultos, los ignorantes, que por su ignorancia religiosa y su comportamiento moral eran tenidos por impuros y, por tanto, tenían cerrada la puerta de acceso a la salvación'21.

Ahora bien, según los datos que nos aporta la Misna, (recopilación de las tradiciones orales judías, siglo II d.C., que más tarde se completó en el Talmud, N. De Cij) el enfrentamiento e incluso la incompatibilidad entre estas dos clases de personas, llegaba, por ejemplo, hasta el extremo de que "si la mujer de un haber deja que la mujer de un 'amme haArez muela en el molino de su casa... la

Mediterranean. American Anthropological Association, Washington (D. C.), 1987. Resumen de este planteamiento, en J. J. Pilch y B. J. Malina, Biblical Social Values and their Meaning, Massachusetlts, 1993, pp. 95-104.

21. La descripción y las características de estas dos categorías de personas se encuentran en J. Bowker, Jesus and the pharisees, Cambridge, 1973, pp. 29-38. Propiamenle, el término haber designaba al miembro de una comunidad larisea, pero después del período neotestamentario se aplicó a los doctores no ordenados. C fr. J. Jeremias, Jerusalén en tiempos de Jesús, pp. 267-268.

Digitalizado por Biblioteca "P. Florentino Idoate, S.J."

Universidad Centroamericana José Simeón Cañas 
casa queda impura"22. Es decir, la observancia o inobservancia de la religión (con los conocimientos religiosos que eso exigía) dividía a la población de tal manera y hasta tales extremos que los observantes no podian ni tratarse con los inobservantes, ya que semejante trato los deshonraba ante la población y ante Dios mismo.

Pues bien, en esta situación, los evangelios nos suministran dalos abundantes de la postura que adoptó Jesús en aquella sociedad y en tales circunstancias. En pocas palabras, Jesús se puso decididamente de parte de todas aquellas gentes que, por una causa o por otra, eran tenidas por indeseables, despreciables, impuras ante Dios y ante los hombres. Estas gentes se resumen en los cuatro grupos antes mencionados: los enfermos, a los que se relacionaba con el pecado y la impureza23; los pobres, que por su ignorancia religiosa no podían cumplir con la ley divina24; los publicanos y pecadores, especialmente marginados y odiados, como ya se dijo; y las mujeres, que en aquella cultura eran las personas más marginadas socialmente25.

Ahora bien, esta postura de Jesús provocó inmediatamente el enfrentamiento con los haber(im), los conocedores de la ley religiosa hasta el último detalle; y los observantes de dicha ley en sus más minuciosas exigencias. Se trata, como sabemos, del enfrentamiento con los "escribas y fariseos", que desembocó finalmente en el enfrentamiento decisivo y mortal con los sumos sacerdotes y ancianos o senadores. Todo esto es bien conocido. $\mathrm{Y}$ no es necesario explicarlo aquí.

Sólo falta explicar una cosa que es delerminante en todo este asunto. Estos cuatro grupos, como ya se ha dicho, no coincidían en su siluación económica. Porque los sumos sacerdoles y senadores eran, casi todos, inmensamente ricos, mientras que los escribas y fariseos eran gente popular, y muchos de ellos, rigurosamente pobres.

22. Toh. 7, 4. Citado por E. Schürer, Historia del pueblo judio en tiempos de Jesús, Vol. II, Madrid, 1985, p. 505, que aduce numerosos ejemplos en este mismo sentido. Op. cit., pp. 503-506.

23. En la teología del Antiguo Testamento, la conexión entre pecado y enfermedad es el presupuesto fundamental de los ritos de purificación. Cfr. G. von Rad, Teología del Antiguo Testamento, Vol. I, Salamanca, 1972, p. 346. Información actualizada, sobre este punto, con bibliografía, en J. Scharbert, Krankheit. II, Alies Testament, en Theologische Realenzyklopädie, Vol. 19, Berlin, 1990, pp. 680-683. En el Nuevo Testamento, la relación enlre enfermedad y pecado está atestiguada claramente: In 5 , $14 ; 9,2 ; 1$ Cor 11,30 ; cfr. Rom 8, 20.

24. De ahi, las listas de oficios despreciados (casi todos asociados a los pobres) que, con frecuencia, llevaban consigo la pérdida de los derechos cívicos y polílicos. Ofrece estas listas y las analiza J. Jeremias, Jerusalén en tiempos de Jesús, pp. 315-323.

25. Un análisis documentadísimo, con abundanle bibliografia, sobre la marginación en que vivian las mujeres, en J. Jeremjas, Jerusalén en tiempos de Jesús, pp. 371-383. A esto hay que añadir los dalos que aporta $\mathrm{E}$. Schüssler Fiorenza, En memoria de ella, Bilbao, 1989. Y los estudios que cita H. Küng, El cristianismo. Esencia e historia, Madrid, 1997 , p. 815 , nota 62 . 
Lo que los unificaba a todos era una actitud religiosa de fondo, que consistía en su saber religiaso (el conocimiento de la Ley) y en su comportamiento religioso (la observancia de lo mandado en la Ley). Este "saber" y este "comportamiento" les daban una conciencia de seguridad y de superioridad, que, en la práctica, los incapacitaba para comprender a las gentes débiles y marginales. $Y$, sobre todo, hacía prácticamente imposible que ellos se acercaran a los débiles, se interesaran sinceramente por ellos, los escucharan, los respetaran en su situación concreta, los quisieran de verdad y, menos aún, se solidarizaran con ellos.

Seguramente, el texto evangélico, que mejor sintetiza todo esto, es la parábola del fariseo y del publicano (Lc 18, 9-14). La parábola describe un lipo de hombres en los que se daban estas tres características: (1) se sentían "seguros" de sí mismos; (2) porque se consideraban "justos", o sea, personas cercanas a Dios; (3) "despreciaban" a los demás (Lc 18, 9). Se trataba, por tanto, de personas en quienes la religión (el convencimiento de estar cerca de Dios) había producido tres efectos: primero, seguridad en sí mismos; segundo, convicción de superioridad con respecto a los que no pensaban y acluaban como ellos; tercero, desprecio hacia quienes vivían de manera distinta a como ellos vivían. $\mathrm{Y}$ estos tres efectos son los que se expresan en la oración del fariseo (Lc 18, 11-12).

Sin duda alguna, lo más peligroso que vio Jesús en los hombres con los que se enfrentó, fue algo aún más profundo que el apego al dinero. Fue la perversión radical del sujeto, la perversión antropológica, que puede producir $\mathrm{y}$, de hecho, produce la religión, cuando se utiliza para afianzarse a sí mismo, para sentirse superiores a los demás y, por consiguiente, para terminar despreciando a todo lo que es debilidad humana en este mundo.

Y esto es lo más peligroso por dos razones. Primero, porque el sujeto, en este caso, ni se puede dar cuenta de lo que realmente le pasa, ni siquiera lo sospecha, sino que se piensa que él es el que está cerca de Dios. Segundo, porque una persona así, se incapacila radicalmente para amar a quien sea, sobre todo si se trata de amar a gente que no coincide con su manera de ver la vida, de pensar y de actuar. Cosa que puede (y suele) ocurrir cuando se trata de gentes marginales, ya sea por motivos económicos, éticos, religiosos, culturales o políticos. En definitiva, cuando se trata de los débiles de este mundo.

\subsection{Los "hombres de la religlon" y los pobres}

Que nadie piense que, al decir todo lo anterior, aquí se está insinuando (y mucho menos, afirmando) que, en la Iglesia actual, siguen presentes los escribas y fariseos como lo estaban en el judaísmo del tiempo de Jesús. Hacer semejante afirmación y establecer semejante paralelismo sería, además de una falsedad manifiesta, una injusticia grave. Esto debe quedar claro, antes que ninguna otra cosa. Porque de sobra sabemos que en la Iglesia (la de hoy y la de siempre) hay cantidades incontables de mujeres y de hombres que viven el espíritu del

Digitalizado por Biblioteca "P. Florentino Idoate, S.J."

Universidad Centroamericana José Simeón Cañas 
evangelio, la mística de Jesús, en el sentido más riguroso y exigente, exactamente en cuanto se refiere a la solidaridad con lo más débil y marginal de este mundo. Esto ante todo.

Pero, si lo que se acaba de decir es cierto, no es menos verdad que sería necesario estar ciegos para no ver el peligro constante, que amenaza a los "hombres de la religión". El peligro consiste en entender y vivir las creencias y las prácticas religiosas de tal manera que, sin darse cuenta el sujeto, viene a reproducirse en él lo mismo que ocurrió en el caso de los fariseos del tiempo de Jesús. Se trata, por lo demás, de algo bastante conocido por casi todo el mundo que, de una manera o de otra, se relaciona con ambientes religiosos. En efecto, es sabido que, en esos ambientes, es frecuente encontrar personas que interiorizan de tal forma las creencias y las prácticas de la religión que, en concreto, resulta lo siguiente: son personas que se sienten seguras de si mismas, a veces con tal seguridad, que por nada del mundo cambiarian la más mínima de sus convicciones religiosas.

Además, precisamente porque se consideran en posesión de la verdad intocable, esas mismas personas, sin darse cuenta, abrigan y hasta defienden celosamente un oscuro (pero muy real) sentimiento de superioridad, sobre todo cuando dan gracias a Dios de haberlas preservado de la mucha desorientación y corrupción que hay en este mundo. Finalmente, aunque les arrancasen la piel a (iras, en modo alguno estarian dispuestos (quienes piensan así) a ser o a vivir como las gentes depravadas, que carecen de la más elemental dignidad: ni dignidad religiosa, ni dignidad ética, ni dignidad social.

Por supuesto, estas cosas no se suelen decir así, por las claras. Pero es un hecho que hay sujelos que sienten y viven estas cosas. Es un hecho que esta clase de sujetos abunda seguramente más de lo que nos imaginamos. Y es un hecho también que todo esto puede ser un producto típico de la religión. Porque es precisamente la especificidad de "lo santo" y "lo sagrado" el determinante último que les da la seguridad que sienten, la superioridad que ocultamente disfrutan y el desprecio profundo que viven. Aunque también es cierto que, nomalmente, no sólo ni se dan cuenta de que viven todo esto, sino que, además (y aquí está lo más peligroso del asunto), quienes van por la vida de esta manera, están profundamente persuadidos de que es así, y sólo así, como tienen que pensar $y$ acluar.

Ahora bien, en la medida en que la religión produce (con relativa frecuencia) este tipo de personas, se comprende por qué, en ambientes religiosos, ocurren cosas que, no sólo resultan difíciles de explicar, sino que además (hablando en cristiano) están en los antípodas del evangelio y, para colmo, se ven con la mayor naturalidad del mundo. Se cumple así, respecto de la religión, aquel profundo refrán latino: corruptio optimi pessima (nada hay peor que la corrupción de lo mejor). 
Pero vengamos a cosas más concretas. Hablamos de los pobres y, en general, de las gentes marginales que abundan en nuestra sociedad. Pues bien, para nadie es un secreto que, por ejemplo, no es raro encontrar "hombres de Iglesia" que se impacientan y hasta se irritan por el simple hecho de una norma litúrgica que se deja de cumplir exactamente en la misa, mientras que, al mismo tiempo, ni se preocupan, ni se acuerdan $y$, por supuesto, no se irritan por el hecho de que haya gente sufriendo y hasta muriéndose de hambre o de abandono cerca, quizá muy cerca, de donde está pasando lo de la misa.

Naturalmente, cuando ocurre una cosa así, cualquiera se tendría que preguntar: pero, ¿qué escala de valores funciona en la vida de quien se porta de esa manera? Y todo el mundo sabe que, en templos, capillas y conventos, se suelen producir más situaciones de impaciencias, irritaciones y disgustos (a veces, hasta con denuncias a las autoridades competentes) por causa de normas litúrgicas que no se cumplen, que por el abandono efectivo y dramático de personas que sufren más de la cuenta. Naturalmente, esto no pasa de ser un ejemplo, que puede parecer intrascendente. Pero si la cosa se piensa a fondo, da pie para sospechar que se trata de algo más grave de lo que algunos se imaginan.

Otro ejemplo más elocuente. Es un hecho que, en ambientes "religiosos", cuando (por la razón que sea) se plantea el tema de los pobres, sobre todo si el tema se trata con cierta profundidad, sin saber exactamente por qué, frecuentemente se crea y se nota un cierto malestar, una especie de inquietud, sospechas y hasta no es raro que se llegue a la tensión manifiesta, con la consiguiente discusión y disgusto de casi todos. ¿Por qué? Es sintomático que este tipo de situaciones no se produzca cuando la cosa no pasa de decir, como es razonable, que hay que "ayudar" a los pobres, "socorrer" a los necesitados, organizar tal o cual campaña de beneficencia, dar limosna en el día del amor fratemo o cosas así. Más aún, cuando la conversación se queda en esos buenos proyectos, los participantes suelen terminar con la conciencia de que están haciendo lo mejor del mundo.

La situación desagradable se produce cuando, como se ha dicho, el tema se trata "con cierta profundidad". Es decir, cuando no nos quedamos en la "ayuda" y la "limosna" (parecidas a aquellas que echaban los ricos en el tesoro del templo (cfr. Mc 12, 41 y $L c 21,1$ ), sino que vamos al fondo de las cosas. Don Helder Cámara, el gran obispo-profeta de Brasil, solía decir: "cuando doy limosna a un pobre, me llaman sanlo; si pregunto por qué es pobre, dicen que soy comunista". Y entonces, ya tenemos el lío. Porque, es claro, hablar de los pobres "a fondo", es hablar de la economía, de la política. Y eso nos lleva enseguida a pronunciamos sobre las derechas y las izquierdas, los socialismos, las dicladuras y las democracias, el capitalismo, el neoliberalismo, las revoluciones y las guerras, en definiliva, los temas más graves que se pueden tratar en esta vida. 
Todo eso, seguramente, explica por qué el tema de los pobres suele resultar confliclivo y puede terminar crispándonos a todos.

Pero aquí estamos hablando de los "hombres de la religión" y los pobres. Y entonces, si es que se produce el malestar y el disgusto mencionados, estamos locando (sin damos cuenta) los estratos más profundos de la persona. Porque hablar de "pobres", desde el punto de vista de la religión y, más concretamente, desde el punto de vista del cristianismo, no es hablar simplemente de una cuestión de "dinero", sino, sobre todo, de un asunto de "poder", de valer y de dignidad.

Ya lo hemos visto, al explicar cómo entendió Jesús lo de los "pobres": a ellos asoció los publicanos y pecadores, los enfermos (con su estrecha asociación cultural al pecado), las mujeres, aun cuando fueran prostitutas, paganas, impuras, adúlteras o samarilanas. O sea, para Jesús, hablar de "pobres" era hablar de gentes "débiles" y "marginales". Y era hablar de esas gentes situándolas en el centro mismo de la vida, en el primer plano de sus proyectos y preferencias.

Ahora bien, eso exactamente es lo que, a los "hombres de la religión", nos resulta "locura" y "escándalo" ( $c f r$. 1Cor 1, 22-25). Porque no toca, ni sólo ni principalmente, a nuestros bolsillos, sino sobre lodo a nuestra dignidad, a nuestro nombre y, más que nada, a nuestra respelabilidad y nuestros pretendidos poderes. A todo aquello que san Pablo llamó después "la justificación" del hombre.

Por eso, en los ambientes eclesiásticos, hay mucha gente dispuesta a "ayudar" a los pobres, incluso a "evangelizar" a los pobres. Pero, seamos sinceros, ¿cuántos "hombres de Iglesia" estamos realmente convencidos de que tenemos que "aprender" de los pobres? ¿Qué nos pueden "enseñar" ellos a nosotros, sobre todo en asuntos tan "técnicos" como es lo de Dios, lo de Jesús, lo del evangelio? ¿Cuántos dirigentes, en la lglesia, están de verdad dispuestos a pedir consejo y asesoramiento a los pobres? Más aún, ¿a quién se le pasa por la cabeza que los pobres ( jde la manera que sea!) tendrían que ser corresponsables en el gobierno de las parroquias, de las diócesis, de la lglesia entera?

Se podrían seguir planteando preguntas de este tipo. Preguntas que, sin duda, a unos les parecerán cosas sin sentido alguno. A otros, les darán la impresión de que todo esto son radicalismos sin pies ni cabeza. $Y$ no faltará quien piense que ni vale la pena hablar de estas cosas. Ahora bien, este tipo de reacciones viene a confirmar que no andan descaminados los que sospechan que el malestar profundo que se ha creado en muchos ambientes eclesiásticos con motivo de la teología de la liberación, tiene su verdadera razón de ser en que, efectivamente, los pobres, no sólo no pintan nada en la Iglesia, sino sobre todo (lo que es más preocupante), son vistos, por no pocos "hombres de la religión", como un "peligro" para la Iglesia.

Digitalizado por Biblioteca "P. Florentino Idoate, S.J."

Universidad Centroamericana José Simeón Cañas 
¿Por qué? Sencillamente, porque dar la palabra a los pobres, conceder protagonismo a los pobres, pretender que la sociedad y las instituciones (incluida la Iglesia) se organicen en función de los criterios y los intereses de los pobres, son cosas que ponen en cuestión nuestra pretendida seguridad, nuestra conciencia de superioridad y nuestro mal disimulado desprecio hacia todo lo que es marginalidad y debilidad en el sistema.

Cuando Jesús les dijo a los "hombres de la religión" de su tiempo que "los publicanos y las prostilutas entran antes que ustedes en el reino de Dios" (Mt 21,31 ), cometió una terrible imprudencia. Porque, además de insultar a aquellos hombres respelables, puso lo de la religión al revés. Y eso es lo que, por lo visto, no nos entra en la cabeza. Porque han pasado cientos de años y muchos "hombres de Iglesia" seguimos empeñados en entrar nosotros los primeros. Y no se trala aquí (como a veces se oye decir) de una mitificación de los pobres -que pueden ser tan pecadores como los publicanos, etc. Se trata de una "desmitificación" ante Dios de nosotros mismos como hombres de lglesia.

\section{Los pobres y la Iglesia}

Con todo lo anterior parece que vamos llegando a las últimas consecuencias. Porque si, efectivamente, no pocos "hombres de Iglesia" reproducimos (seguramente sin sospecharlo) el tipo de deformación religiosa que denunció Jesús, entonces, tendremos que reconocer que semejante deformación no afecta sólo a las personas. Eso se refleja inevitablemente, de una manera o de otra, también en la institución. Sobre todo, si tenemos en cuenta que, al hablar de "hombres de Iglesia", estamos hablando sobre todo de "dirigentes", los que (por una razón o por otra) tenemos responsabilidad, autoridad, en definitiva, "poder" en la Iglesia.

Pero, antes de seguir, una advertencia. Es decisivo recordar, una vez más, que, al hablar de este asunto, no se trata, ni por un instante, de poner en cuestión (y mucho menos, negar) la estruclura jerárquica de la Iglesia.

El problema no está en la estructura. El problema está en la organización y en el funcionamiento de esa estructura. Es decir, no es cuestión de una verdad dogmática, sino de cómo, "en la práctica", se ha organizado y funciona el "poder" eclesiástico. Cualquiera que haya leído un manual de historia de la Iglesia, sabe perfectamente que el asunto del poder eclesiástico se ha gestionado de maneras muy distintas a lo largo de los siglos. Esa simple constatación quiere decir, entre otras cosas, que lo que se hace ahora, se podría hacer de maneras muy distintas.

Esto supuesto, se trata ahora de explicar lo que, según parece, es lo más determinante en la relación de la Iglesia con los pobres. O, para precisar más el tema: lo más determinante en la relación de las autoridades eclesiásticas con los pobres. 


\subsection{No es problema de personas, sino de estructuras mundiales}

Ante todo, es un hecho, de sobra conocido, que hay muchos, muchísimos, obispos, sacerdotes y religiosos (mujeres y hombres) que, ahora mismo, están entregando su vida a los pobres con una generosidad a toda prueba. Pero, con decir eso, no se responde a la cuestión que aquí nos interesa. Porque el problema no. está en si hay más o menos generosidad en determinados eclesiásticos. Tampoco está el problema en si la Iglesia tiene más o menos instituciones caritativas que, evidentemente, alivian el sufrimiento de mucha gente.

La cuestión es más de fondo. Es el sistema económico mundial, más concretamente el neoliberalismo, el que ha provocado que, en este momento, haya más de mil millones de personas abocadas al exterminio por causa del hambre.

Concretando más, todo el mundo sabe que, en este final de milenio, se están desarrollando, a rilmo acelerado, dos fenómenos asombrosos: la globalización y la exclusión. Sabemos que la globalización es, ante todo, un fenómeno económico: la economía y el mercado están de tal manera interconectados, que no hay rincón de la tierra que se escape a su influencia. Pero sabemos también que esa influencia no es igual para todos. Porque la globalización se ha organizado en beneficio de algunos, pero precisamente a base de excluir a otros muchos.

Se sabe, con seguridad, que la economía actual ofrece posibilidades reales para cubrir las necesidades básicas de todos los seres humanos. Pero se sabe igualmente que la globalización está, de hecho, organizada, controlada y dirigida por la tríada que forman Europa, Estados Unidos y Japón. Ahora bien, esa tríada ha organizado el sistema económico mundial de tal manera que, en la práctica, dos tercios de la humanidad quedan excluídos de los beneficios de la globalización. Con una puntualización que es fundamental: los excluidos están por todas partes, en los países ricos y en los países pobres, en el primer mundo y en el tercero. Naturalmente, la cantidad de excluidos, en los paises subdesarrollados, es abrumadora, puesto que alcanza a la casi totalidad de la población. Mientras que en los países opulentos, los excluidos son las gentes marginales que forman el llamado "cuarto mundo". Pero tengámoslo muy presente: los excluidos están cada día a la puerta de nuestra casa.

Por otra parte, nunca deberíamos olvidar que los excluidos son el resultado inevitable de la voracidad del sistema, que se encama en instituciones y en personas concretas, en gobemantes, en magnates financieros, en consejeros y planificadores de la gestión de las multinacionales.

No seamos ingenuos. No se trata de algo que ha resultado sin saber cómo ni por qué. Todo esto ha sido efecto de cálculos, estudios y planificaciones hechas por hombres concretos, por personas con su rostro bien definido y, por supuesto, con sus cuentas corrientes repletas, hasta reventar, en las instiluciones bancarias 
más seguras del mundo. $Y$ esto, que ya es dramático en sí mismo, resulta sencillamente insoportable y sangrante cuando se produce en países pobres, por ejemplo, cuando determinados gobernantes acumulan riquezas asombrosas a costa de la miseria y la muerte de poblaciones enteras. Así están las cosas en este momento.

\subsection{La institución eclesiástica ante las estructuras mundiales}

Y entonces, la cuestión es: ¿cómo se sitúa la institución eclesiástica y cómo actria ante los poderes políticos y económicos que, de una manera o de otra, son responsables de este estado de cosas? A nivel teórico, ya se sabe: la "doctrina social" de la Iglesia es clara y elocuente, exigiendo justicia y solidaridad para todos. Pero, en este orden de cosas, las teorías tienen un poder muy limitado. El problema está en saber lo que hace (y deja de hacer) la instilución eclesiástica a nivel práctico.

Pero, ¿puede hacer algo más de lo que hace? Aquí, sin duda alguna, está el nudo de la cuestión. En definitiva, todo depende de cómo se organiza y se gestiona el "poder eclesiástico". Y también de cómo se sitúa ese poder ante los otros poderes, el "poder económico" y el "poder político". Ahora bien, llegados a este punto, no hay más remedio que descender a cosas muy concretas, que son, sin duda alguna, las más elocuentes. Por ejemplo, ¿cómo se eligen los obispos en la Iglesia? Es decir, ¿qué criterios se tienen en cuenta a la hora de designar a los hombres más determinantes en el comportamiento de la institución elesiástica? Es evidente que aquí estamos tocando una cuestión vital. Porque si las cosas se organizan para que resulte tal tipo de obispos, es porque se quiere tal tipo de Iglesia.

Pues bien, se sabe con seguridad que, al menos en ciertos países del tercer mundo, cuando los nuncios de la Santa Sede piden informes secrelos, para elegir un candidato al episcopado, se pregunta, entre otras cosas, si el candidato en cuestión mantiene buenas relaciones con los gobernantes y con los militares del país. Es evidente que, en esto, se pone al descubierlo uno de los puntos más oscuros y preocupantes que, en este momento, presenta la organización de la institución eclesiástica. Porque el mundo entero sabe de sobra hasta qué niveles de corrupción han llegado, en los úllimos tiempos, no pocos gobernanles y no pocos militares, en este siglo patéticamente ensangrentado, las más de las veces, por causa de esas personas.

$Y$, entonces, nos encontramos con lo siguiente: por una parte, la Iglesia publica documentos brillantes, exigiendo justicia y respeto a los derechos humanos; pero, al mismo tiempo que dice eso, organiza las cosas de tal manera que se ponen todos los medios necesarios, incluso exigiendo secretos severísimos y hasta amenazando con penas de excomunión (sic), para que, quienes mandan en la Iglesia, sean hombres que se llevan bien con los 
responsables más directos de las mayores injusticias y de los atropellos más brutales a los derechos humanos. ¿Cómo extrañarse entonces de que luego surjan terribles acusaciones de connivencia de algunas jerarquías con poderes criminales (caso, por ejemplo, de Argentina) o, por el contrario, surjan también desconfianzas de la institución ante obispos que resultan incómodos a los poderes de este mundo (casos de Brasil o de Mons. Romero)?

Estando así la situación, a cualquiera se le ocurre esta pregunta: ¿qué es lo que, a la hora de la verdad, quiere realmente esta Iglesia? ¿Defender su poder o defender a las victimas de los poderes de este mundo? Resulta muy doloroso tener que hacerse esta pregunta. $\mathrm{Y}$, sobre lodo, tener que hacérsela en público. Pero las cosas han llegado a tal extremo, que, callarse ante esta situación, sería hacerse cómplice de ella. Por honestidad, por coherencia, si pretendemos ir por la vida con la dignidad que se puede y se debe exigir a todo ser humano, no podemos olvidar que semejante complicidad es la palanca más eficaz que necesita el sistema para proseguir su escalada de barbarie, a costa de tanto sufrimiento humano. Por supuesto, no es "prudente" decir estas cosas. Y es probable que de ello se van a seguir no pocos "inconvenientes". La cuestión está en saber si, en un momento determinado, lo más aconsejable es la "prudencia" o la "audacia" (parresia, según el Nuevo Testamento). Ahora mismo, cuando hay en juego tanto dolor, tanta humillación y tanta muerte, parece que el único camino razonable es el de la parresia. Porque los inconvenientes, que se sigan, por muy fuertes que sean, pasan sin duda alguna a segundo término.

\section{Las estructuras eclesiásticas}

Por otra parte, los "recelos" y hasta los "miedos" de la institución eclesiástica a los pobres, a las gentes marginales del sistema, se manifiestan también de otra manera: en la abierta resistencia de los dirigentes eclesiásticos a que los pobres intervengan, participen o se sientan corresponsables en el gobiemo de la Iglesia.

De ahí, el rechazo de la institución a lo que, en el fondo, han representado, en los últimos treinta años, las comunidades eclesiales de base y sus propuestas de una Iglesia "de los pobres", una Iglesia "del pueblo" o cosas parecidas. Que sepamos, estas comunidades jamás han pretendido organizar una Iglesia "paralela". Jamás han querido constiluirse en "sectas". Jamás han rechazado la auloridad de los obispos. Entonces, ¿a qué vienen los miedos y los recelos de la institución ante las gentes más desgraciadas de este mundo?

Cualquier manual de historia de la Iglesia informa abundantemente de que en ella han influido (más de lo que imaginamos) emperadores, señores feudales, reyes y magnates, gobemantes y políticos, dictadores y hasta tiranos con las manos manchadas de mucha sangre humana. Con demasiada frecuencia, se toleraron esas cosas y hasta se yieron con buenos ojos en las _altas esferas del

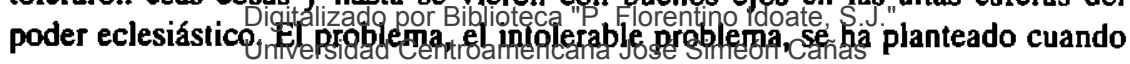


han sido los pobres, los miserables de este mundo, los que han pretendido cometer la osadía de decir ellos su palabra, de participar (siquiera de alguna forma) en las decisiones parroquiales o en la orientación general de las diócesis. Cuando ha ocurrido eso, se ha encendido la luz roja de alarma. Y se han puesto todos los medios necesarios para frenar semejante peligro. Por eso, entre otras cosas, se ha visto, en la teología de la liberación, una amenaza tan grave. Por eso, se ha hecho lo posible por frenar o modificar la influencia del CELAM en América Latina.

Por eso, los nombramientos de obispos se han preparado con un criterio selectivo, en orden a que no se repita lo de Medellín, ni siquiera lo de Puebla. En fin, está visto (lo que está pasando en la Iglesia lo demuestra hasta la evidencia) que los pobres son vistos, por hombres influyentes en la instilución eclesiástica, como un peligro serio que amenaza a la Iglesia.

Para concluir, se confirma que, efectivamente, lo más grave, lo más peligroso, que vio Jesús en la condición humana, no es el apego al dinero y sus consecuencias, sino el apego al poder que el dinero procura26. Y esto, en un sentido concreto: en cuanto que el poder, transfigurado por la religión, se convierte en "orgullo religioso". Es lo que san Pablo expresa con la palabra káuchêsis (y sus derivados). Esta palabra indica la experiencia en la que el ser humano (la mayor parte de las veces, sin darse cuenta) define y determina su actitud más profunda ante Dios. Porque, en la káuchêsis, el hombre manifiesta en qué confía y en qué se basa en su vida, sobre qué cimienta su existencia27. En otras palabras, la káuchêsis expresa dónde tiene puesta cada uno, en última instancia, su seguridad28. En este sentido, se puede y se debe hablar de un orgullo "religioso", porque es la experiencia básica, que nos remite a "lo último", lo que, en definitiva, determina nuestra vida.

Pues bien, cuando lo que verdaderamente delemina la vida de un hombre es su afán y su empeño por la propia seguridad, la superioridad, el poder, con el inevitable desprecio que eso lleva consigo hacia los "débiles", entonces, por más

26. Recuérdese que san Ignacio, en sus Ejercicios, describe asi el funcionamiento de la bandera de Satanás: primero riquezas, de ahí al poder y al "vano honor". Y de ahj "a todos los pecados".

27. J. Zmijewski, "Kaucháomai", en H. Balz, G. Schneider, Diccionario exegético del Nuevo Testamento, Vol. I, Salamanca, 1997, p. 2283.

28. Se trata (por cilar un pasaje fundamental) de la experiencia que analiza y censura, con tanta dureza, san Pablo en el capítulo segundo de la carta a los Romanos: cuando el hombre pone su seguridad en el propio comportamiento "religioso" (en la "ley", Rom 2,23 ), se produce un tipo de persona enormemente peligrosa. Porque: (1) se considera superior a los que no proceden como él (Rom 2, 17-20), hasta el punto de erigirse en juez de los otros (Rom 2, 1); (2) eso genera un corazón endurecido (sklerbiesa) (Rom 2,5); (3) todo eso desemboca en el auloengaño y en la incoherencia, pues creyéndose maestro y guía de los demás (Rom 2, 19-20), en realidad se porta de lal manera (Rom 2, 2l-23), que lodo termina en que la gente, "por culpa" del que actúa asi, "maldice el nombre de Dios" (Rom 2, 24).

Digitalizado por Biblioteca "P. Florentino Idoate, S.J."

Universidad Centroamericana José Simeón Cañas 
que todo esto se revista e incluso se mistifique de "religión" y hasta de "servicio a la Iglesia", nos encontramos con la reproducción exacta de aquello con lo que se enfrentó Jesús. Sin duda alguna, porque en ello vio el peligro más grave para la humanidad. De ahí nace el desprecio concreto y próctico hacia lo débil de este mundo. Es decir, ahí exactamente tiene su punto de partida la tragedia y la muerte de los pobres. Hasta ese punto es decisiva la relación de los pobres y la Iglesia.

\section{Conclusión}

¿Qué piden los pobres a la Iglesia? ¿Qué desafío le plantean para el nuevo milenio? Resumamos lo que hemos ido encontrando.

En primer lugar, que no les tenga miedo, que no los desconsidere a la hora de pensar, decidir, actuar, enseñar, etc.

Que les dé, como mínimo, tanta beligerancia y tanta audiencia como presta a muchos poderosos de este mundo (ricos, sabios, gestores de este orden presente...). Como mínimo, tanta. Debería otorgarles mucha más.

Que los haga, no sólo sujetos pasivos de su atención, sino sujetos activos: encaminándose a hacerlos presentes en sus centros de análisis y de decisión, etc.

Que no persiga y maltrate a todos aquellos que optan por los pobres (con todas las consecuencias que eso lleva consigo) y tratan de construir un mundo menos cruel y menos injusto para con ellos.

Y que, convertida a Dios, no ponga su seguridad más en el apoyo ambiguo de los poderes de este mundo, que en el apoyo débil de los pobres. Y sepa que, si esto le crea problemas, también se los creó a su Fundador. 